\title{
A INFLUÊNCIA DAS CARACTERÍSTICAS DO CONSELHO DE ADMINISTRAÇÃO, COMITÊ DE AUDITORIA E CONSELHO FISCAL NO AUDIT DELAY
}

\section{THE INFLUENCE OF THE CHARACTERISTICS OF THE BOARD OF DIRECTORS, AUDIT COMMITTEE AND FISCAL COUNCIL ON AUDIT DELAY}

\author{
MARIANE ALVES BORBA \\ Universidade Tecnológica Federal do Paraná - UTFPR - Campus Pato Branco \\ Bacharel em Ciências Contábeis - UTFPR \\ Orcid: https://orcid.org/0000-0002-3301-8480 \\ E-mail: mariane.g97@hotmail.com \\ Endereço: Via do Conhecimento Km 01 - CEP 85.503-370 - Pato Branco - PR
}

MAYARA DIANA DOS SANTOS

Universidade Tecnológica Federal do Paraná - UTFPR - Campus Pato Branco

Bacharel em Ciências Contábeis - UTFPR

Orcid: https://orcid.org/0000-0002-2760-7545

E-mail: may.dianasantos@gmail.com

\section{LUCIANE DAGOSTINI}

Universidade Tecnológica Federal do Paraná - UTFPR - Campus Pato Branco

Doutoranda em Ciências Contábeis - UFPR

Orcid: https://orcid.org/0000-0002-9351-8778

E-mail: lu.dagostini2020@gmail.com

\section{ELIANDRO SCHVIRCK}

Universidade Tecnológica Federal do Paraná - UTFPR - Campus Pato Branco

Doutor em Administração - UFSC

Professor no Departamento de Ciências Contábeis da UTFPR - Campus Pato Branco

Orcid: https://orcid.org/0000-0003-1957-9115

E-mail: eliandrosc@gmail.com

\begin{abstract}
RESUMO
A governança corporativa é um conjunto de medidas que objetiva aumentar a probabilidade de o investidor garantir o seu retorno, é preciso ter um mecanismo de incentivo e controle para que se minimize a presença de prejuízos causados pelos conflitos de interesse entre gestores e investidores. Como exemplos de mecanismos de governança corporativa podem citar o Conselho de Administração, o Comitê de Auditoria e Conselho Fiscal, que é um órgão fiscalizador independente da diretoria e do Conselho de Administração. A função dos mecanismos de governança corporativa é importante na divulgação das informações das empresas no tempo certo, visto que as informações financeiras desempenham papel relevante em relação ao mercado e aos investidores e o atraso compromete a confiabilidade na organização. Por conseguinte, essa pesquisa se propôs verificar a relação entre audit delay e as características do Conselho de Administração, Comitê de Auditoria e Conselho Fiscal das empresas listadas na B3. Consiste em um estudo descritivo, de caráter documental e
\end{abstract}

Data de submissão: 11/11/2019. Data de aceite: 09/12/2019. Data de publicação: 17/12/2019.

Artigo selecionado no fast track do COGECONT - International Conference in Management and Accounting, realizado na Universidade Comunitária da Região de Chapecó - Unochapecó, Chapecó - SC, de 17 a 19/10/2019. 
abordagem quantitativa. Realizadas nas empresas listadas que possuem Comitê de Auditoria, nos segmentos Novo Mercado, Níveis 2 e 1, no período de 2014 a 2016. Os resultados apontaram relacionamento negativo do audit delay com número de membros do Comitê de Auditoria, com a existência de Conselho Fiscal, com a rentabilidade do ativo e com o porte da empresa. O número de membros do Conselho Fiscal possui significância positiva e ressalta uma relação direta com o audit delay. As variáveis relacionadas ao Conselho de Administração não apresentaram significância com o audit delay.

Palavras-chave: Governança Corporativa. IBGC. Audit Delay.

\begin{abstract}
Corporate governance is a set of measures that aims to increase the likelihood that the investor will guarantee his return, an incentive and control mechanism is needed to minimize the presence of losses caused by conflicts of interest between managers and investors. Examples of corporate governance mechanisms include the Board of Directors, the Audit Committee and the Fiscal Council, which is an independent supervisory body of the Board of Directors and the Board of Directors. The role of corporate governance mechanisms is important in disclosing company information in a timely manner, as financial information plays a relevant role in relation to the market and investors, and the delay compromises reliability in the organization. Therefore, this research aimed to verify the relationship between audit delay and the charOacteristics of the Board of Directors, Audit Committee and Fiscal Council of companies listed in B3. It consists of a descriptive study, of documentary character and quantitative approach. Performed in the listed companies that have an Audit Committee, in the Novo Mercado segments, Levels 2 and 1, from 2014 to 2016. The results showed a negative relationship between the audit delay and the number of members of the Audit Committee, the existence of a Fiscal Council, the profitability of the asset and the size of the company.
\end{abstract}

Keywords: Corporate Governance. IBGC. Audit Delay.

\title{
1 INTRODUÇÃO
}

A relação de agência é caracterizada como um contrato entre uma ou mais pessoas, o principal e o agente, consistindo na realização de um trabalho em favor do principal, em que o agente possui algum tipo de autoridade na tomada de decisão (JENSEN, MECKLING, 1976).

Silveira (2004) relaciona que quando existe a separação entre propriedade e controle, existe o risco de os recursos dos investidores não serem empregados de forma correta. Pois, quem fornece o capital não participa de forma direta das decisões tomadas na organização. Surgindo assim a assimetria informacional, que diz respeito à informação que o agente possui e a que é repassada ao principal. O problema que surge entre o principal e o agente, diante da separação de propriedade e controle organizacional, faz surgir à relação de agência, discutido pela Teoria da Agência (JENSEN, MECKLING, 1976).

A governança corporativa compõe-se por meio da relação entre acionistas e órgãos de controle das organizações, visando atender os objetivos da empresa otimizando o desempenho e fornecendo garantias de continuidade do capital para todas as partes envolvidas (CUNHA, 2011). Desta maneira, a governança corporativa é vista como um conjunto de medidas que tem como objetivo aumentar a probabilidade de o investidor garantir o seu retorno (SILVEIRA, 2004). 
Desse modo, para que se minimize a presença de prejuízos causados pelos conflitos de interesse entre gestores e investidores, é preciso ter um conjunto de mecanismos de incentivo e controle, chamado de governança corporativa. Tendo como mecanismos de governança o Conselho de Administração, o Comitê de Auditoria, política de remuneração, equilíbrio de poder, entre outros (SILVEIRA, 2004).

A função atribuída aos comitês é dar suporte ao Conselho de Administração, dando orientação geral nas atividades e decisões estratégicas. Dentre estes, está o Comitê de Auditoria, que auxilia no controle da qualidade das demonstrações financeiras e controles internos. Visando que as informações sejam íntegras e confiáveis, sempre monitorando o cumprimento das leis, regulamentos e sistemas da organização. Tendo como objetivo a proteção dos acionistas e demais usuários da informação contábil (IBGC, 2009).

Diante do exposto, o auditor deve analisar as demonstrações financeiras da empresa de forma imparcial para em seguida elaborar o seu relatório. Entretanto, pontua-se como um ponto negativo o fato de que a eficiência da auditoria pode ser influenciada quando há um atraso na entrega do relatório pelos auditores. Com isso, as informações repassadas aos investidores podem perder relevância devido à falta de tempestividade das informações, gerando um conflito entre os preparadores e os usuários das informações financeiras da entidade. Este período, que diz respeito ao fim do ano fiscal e o fim do trabalho da auditoria, referenciado com a data do relatório é chamado de audit delay (CUNHA, et al., 2015).

O Conselho Fiscal também faz parte dos órgãos de fiscalização e controle da organização. Consiste em um meio de fiscalização independente dos administradores, eleito para se reportar aos sócios, cujo principal objeto é preservar o valor da organização. Dentre suas atribuições está a de analisar as demonstrações financeiras periodicamente e opinar sobre elas, fiscalizar os atos dos administradores, verificando o cumprimento dos deveres legais (IBGC, 2007).

Levando em consideração que o Comitê de Auditoria e o Conselho Fiscal visam garantir que as informações das demonstrações contábeis cheguem aos usuários de forma transparente e fidedigna, elabora-se o seguinte problema de pesquisa: Qual a relação das características do Conselho de Administração, Comitê de Auditoria e Conselho Fiscal das empresas listadas na B3 com audit delay? Com o propósito de responder a essa questão, o objetivo do estudo é verificar a relação entre as características do Conselho de Administração, Comitê de Auditoria e Conselho Fiscal das empresas listadas na B3 com o audit delay.

Esta pesquisa busca contribuir demonstrando que o audit delay pode ser influenciado pelas características dos mecanismos de governança corporativa presentes nas empresa listadas nos três níveis de governança corporativa. Diferencia-se dos demais estudos pela inclusão do Conselho Fiscal, em que é preciso levar em consideração que este é previsto pela legislação societária, porém é instalado mediante solicitação do quadro de acionistas. E, dentre suas atribuições previstas legalmente estão a fiscalização, análise e opinião sobre o conteúdo das demonstrações financeiras elaboradas e divulgadas pelas empresas. Podendo assim vir a ser influente quando se trata da divulgação do relatório de auditoria independente, justamente por suas atribuições fiscalizatórias.

Outras pesquisas estudaram a relação dos mecanismos de governança corporativa com o audit delay (AFIFY, 2009; IKA, GHAZALI, 2012; CUNHA et al., 2015; CUNHA, PLETSCH, SILVA, 2015; CAMARGO, FLACH, 2016; OUSSII, TAKTAK, 2018). Entretanto, relacionam as características do Conselho de Administração ou Comitê de Auditoria, que são mecanismos que devem ser adotados pelas empresas listadas (IBGC, 2007) e não abordam as características do Conselho Fiscal, com o audit delay. Pois, conforme dispõe Art. 161, da Lei 
6.404/76, "a companhia terá um conselho fiscal e o estatuto disporá sobre seu funcionamento, de modo permanente ou nos exercícios sociais em que for instalado a pedido de acionistas". Sendo assim, toda S.A. deve possuir um conselho fiscal, sendo facultado o seu funcionamento pelos acionistas.

\section{REVISÃO DA LITERATURA}

Apresenta-se aqui, o embasamento teórico relacionado com a temática abordada. Sendo que concerne a abordagem relacionada aos mecanismos de Governança Corporativa, Audit Delay e a construção das hipóteses da pesquisa.

\subsection{MECANISMOS DE GOVERNANÇA CORPORATIVA}

O principal objetivo da governança corporativa é "a proteção dos interesses dos acionistas, contra o comportamento do gestor, e dos acionistas minoritários contra ações despóticas dos acionistas controladores" (GOTAÇ, MONTEZANO, LAMEIRA, 2015, p. 410). Sendo formada por mecanismos que visam minimizar os custos de agência, por meio da formação do Conselho de Administração, o qual tem a função de tomar importantes decisões dentro da organização além de monitorar os gestores (MARTINEZ, 2001).

De acordo com o art. 138 da Lei № 6.404, de 15 de dezembro de 1976, o Conselho de Administração é um órgão de deliberação colegiada e sua existência é obrigatória nas companhias abertas e de capital autorizado. Sua atuação deve ter por base a diminuição de conflitos e a redução dos conflitos de agência (KASHIO, 2007). Além de que é o principal órgão de governança, pois é responsável pelo processo de gestão, definição estratégica, orientação geral e plano de ação da organização, é ainda um órgão de ligação que orienta e supervisiona a relação da gestão com as partes interessadas, recebe poderes de tomada de decisão dos sócios e acionistas e presta conta aos mesmos (IBGC, 2008).

No que tange a composição do conselho, é fortemente recomendada pelos códigos de governança corporativa ser composto por membros externos, de forma a melhorar a tomada de decisões. Neste sentido, Fama e Jensen (1983) pontuam que os conselheiros independentes são capazes de suportar as pressões da empresa em relação à manipulação de resultados, sendo assim, os interesses de todos os acionistas são preservados.

Ainda, para que haja melhor desempenho de sua função, o Conselho de Administração conta com comitês acessórios, sendo que a função destes é de lhe dar suporte, por meio de orientação geral das atividades e nas decisões estratégicas. Dentre estes comitês estão, o Comitê de Auditoria, Governança e Indicação, Remuneração entre outros, que tem como objetivo apoiar na resolução de assuntos específicos (B3, 2016).

O Comitê de Auditoria é um dos órgãos de apoio do Conselho de Administração, que também presta informações à auditoria interna e à auditoria externa (ou independente) que é a principal responsável pela certificação de autenticidade das informações que são geradas pela empresa e transmitidas para seus stakeholders (DE LUCA et al., 2010).

Sorrentino, Vicente e Teixeira (2016) destacam que após a promulgação da SOX, o Brasil começa a tratar o Comitê de Auditoria como uma obrigatoriedade legal. A adoção da regulamentação acerca deste, parte do órgão no qual a organização está submetida e as entidades que trazem essas determinações normativas são: o Conselho Monetário Nacional (CMN) via Banco Central, o Conselho Nacional de Seguros Privados (CNSP) por meio da Susep, além das orientações trazidas pelo IBGC e pela CVM. 
Diante do exposto, Santos (2009, p. 40) pontua que o "Comitê de Auditoria tem a missão de avaliar o desempenho econômico-financeiro de uma entidade contábil num determinado período. Funcionando como um órgão consultivo do Conselho de Administração e tendo como uma de suas atribuições que seja formado, preferencialmente, por seus membros (BAIOCO, 2015). Também, sobre suas atribuições, Ika e Ghazali (2012) corroboram que a divulgação pontual dos relatórios financeiros faz com que o Comitê de Auditoria se torne mais eficaz. Abordam também que a independência dos membros do comitê, a formação na área contábil, de auditoria ou finanças (expertise) e o tamanho do Comitê de Auditoria são as variáveis determinantes utilizadas para medir tal eficácia analisada nessa pesquisa.

Outro mecanismo de governança é o Conselho Fiscal que pode ser definido como um órgão fiscalizador independente da diretoria e do Conselho de Administração, que visa contribuir para um melhor desempenho da organização. Objetiva fiscalizar os órgãos da administração e opinar sobre as demonstrações contábeis (IBGC, 2007). De Luca et al., (2010, p. 111) ressaltam "que o Comitê de Auditoria e o Conselho Fiscal são instrumentos distintos de governança. O Conselho Fiscal é independente e tem o propósito único de servir aos acionistas, enquanto o Comitê de Auditoria dá suporte ao Conselho de Administração".

De acordo com Furuta (2010, p. 65) é "um órgão de fiscalização da própria gestão da companhia, eleito pela Assembleia Geral dos acionistas". Para Baioco e Almeida (2017) o Conselho Fiscal é um órgão instalado pela assembleia geral, ele não está vinculado a nenhum outro órgão da organização, é um mecanismo autônomo e presta contas somente aos acionistas por meio de assembleias. Suas ações são estruturadas perante a fiscalização da companhia.

De forma que a atuação conjunta dos mecanismos de Governança Corporativa nas organizações contribuí para que estas divulguem informações aos seus diversos usuários com confiabilidade e transparência nas demonstrações financeiras. Atuam também junto a auditoria independente, mais precisamente o Comitê de Auditoria e o Conselho Fiscal, corroborando para que as demonstrações financeiras estejam de acordo com a realidade vivida pela empresa. Neste sentido, a atuação dos mecanismos de Governança Corporativa pode vir a ser influentes quanto ao prazo de divulgação do relatório de auditoria independente.

\subsection{AUDIT DELAY}

O prazo entre o encerramento do exercício e a emissão do relatório da auditoria independente é internacionalmente conhecido com o termo audit delay (NG, TAY, 1994). Além de que esse pode indicar fatores de risco na organização, originado de controles internos, qualidade das informações demonstradas nos relatórios financeiros e integridade dos gestores, o que faz com que o trabalho da auditoria aumente, atrasando assim a emissão do relatório (MANDE, SON, 2011).

Conforme Habib e Bhuiyan (2011), o processo de adoção às normas internacionais de contabilidade, as IFRS (International Financial Reporting Standards), aumentaram o audit delay das empresas, uma vez que a complexidade dessas normas exige maior tempo de trabalho do auditor. Já, para Carslaw e Kaplan (1991), Ng e Tai (1994) e Bowrin (1998) o tamanho da organização influencia no atraso do auditor, ou seja, ter pressa não é aconselhável quando se trata de auditoria. Pois, a demora pode representar diminuição dos riscos de a informação contábil ser apresentada de forma divergente (PEREIRA, 2011).

Ressalta-se que o audit delay também sofre influência do Comitê de Auditoria, ou seja, quanto maior e quanto mais membros independentes e com conhecimentos específicos em 
finanças, contabilidade e auditoria, menor será o prazo de entrega do parecer (CUNHA, et al., 2015). Também, Ashton, Willingham e Eliot (1987) apuraram que as empresas que possuem opiniões modificadas possuem atraso significativamente maior do que as empresas que possuem relatórios não modificados. Também divulgação do resultado em lucro ou prejuízo afetou o audit delay (CARSLAW, KAPLAN, 1991).

Reporta Pereira (2011, p.19) que "se o audit delay é elevado, é possível que a percepção de risco de informação de desempenho piore para as companhias e as firmas. Investidores podem vender as ações ou exigir uma remuneração maior." Inferindo que o audit delay alto adverte que a organização possui algum tipo de problema em seus relatórios financeiros e demonstrações contábeis (CUNHA, et al., 2015).

Neste sentido, Ika e Ghazali (2012), apuraram que os indicadores de endividamento, liquidez corrente e retorno sobre o ativo tem influência no atraso do relatório de auditoria, aumentando o tempo de publicação das demonstrações financeiras. Também de acordo com Iyoha (2012) quando existem lucros as empresas tendem a divulgar os resultados mais rapidamente e tendem a atrasar quando há prejuízos.

Da mesma forma que Oladipupo (2011) verificou a relação entre as características da empresa auditada sendo elas: tamanho, dívida, patrimônio líquido, rentabilidade, honorários de auditoria e classificação setorial e o audit delay, os resultados encontrados são positivos para todas as variáveis e o atraso do relatório de auditoria. Entretanto, de acordo com Al-Ajmi (2008) o tamanho da empresa, rentabilidade e alavancagem, são fatores determinantes para a divulgação dos relatórios de auditoria sem atraso.

Consoante ao exposto, para Solomon, Reckers e Lowe (2005), os serviços de não auditoria afetam a qualidade das demonstrações financeiras e a independência do auditor. Cunha et al., (2015) concluíram que as empresas que são auditadas pelas Big Four apresentam um prazo de divulgação das demonstrações financeiras menor. Ou seja, as firmas de auditoria Big Four apresentam relação significativa em relação ao prazo do relatório de auditoria. Já em relação aos honorários de não auditoria isso influenciam em um prazo maior na divulgação das demonstrações financeiras. Na sequência são apresentadas das hipóteses de pesquisa.

\subsection{CONSTRUÇÃO DAS HIPÓTESES DE PESQUISA}

Diversos fatores são apontados na literatura que influenciam o audit delay. Dentre eles podemos destacar os mecanismos de Governança Corporativa. O estudo de Afify (2009), em uma amostra de 85 empresas egípcias do ano de 2007, analisou os impactos da governança corporativa no atraso do relatório do auditor independente, obteve-se resultado positivo em relação à independência e dualidade de Conselho de Administração com o prazo de entrega do relatório da auditoria. Nesse sentido, apresenta-se a primeira hipótese de pesquisa:

$H_{1}$ : As características do Conselho de Administração influenciam no atraso de emissão de relatório de auditoria independente das empresas auditadas.

Segundo Ika e Ghazali (2012), um fator importante para a pontualidade na divulgação dos relatórios financeiros é a eficácia do Comitê de Auditoria. Para medir a eficácia analisaram o tamanho do Comitê de Auditoria, a independência, a formação na área contábil, auditoria ou finanças dos membros que compõe o comitê, a realização de reuniões pelo menos quatro vezes por ano e se as informações eram divulgadas voluntariamente.

Para Krishnan (2005), as características do Comitê de Auditoria, afetam a qualidade dos controles internos. Um controle interno de qualidade pode influenciar positivamente o tempo de trabalho do auditor, pois terá um menor tempo despendido nos trabalhos de 
auditoria, influenciando assim o prazo de divulgação das demonstrações financeiras. Desta forma formula-se a segunda hipótese:

$\mathrm{H}_{2}$ : As características do Comitê de Auditoria influenciam no atraso de emissão de relatório de auditoria independente das empresas auditadas.

Fontes Filho (2004) defende que é de competência do Conselho Fiscal exercer a fiscalização sobre o Conselho de Administração da empresa, no que diz respeito às contas e a regularidade dos atos dos gestores, para que haja a prestação de contas aos acionistas de

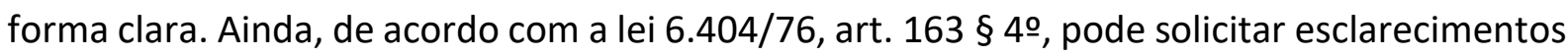
ou informações aos auditores independentes para apuração de fatos específicos, além de analisar as demonstrações financeiras elaboradas ao menos trimestralmente. Podendo assim, ocasionar atrasos nos trabalhos dos auditores independentes e em contrapartida, representa segurança para as informações publicadas. De acordo com Lamb (2002), as atribuições do Conselho Fiscal vão além das previstas na legislação, ele precisa desempenhar a função de controle, acompanhamento e fiscalização dos controles internos além do planejamento estratégico e orçamentários. Desta maneira elabora-se a hipótese:

$\mathrm{H}_{3}$ : O Conselho Fiscal influencia no atraso de emissão de relatório de auditoria independente das empresas auditadas.

A seguir, são apresentados os procedimentos metodológicos utilizados para testar as hipóteses elencadas para a pesquisa, bem como o teste das variáveis de controle atribuídas.

\section{PROCEDIMENTOS METOdOLÓGICOS}

Em conformidade com o objetivo proposto, a pesquisa caracteriza-se como descritiva, com procedimento documental e abordagem quantitativa. Assim, verificou-se a relação entre audit delay e as características do Conselho de Administração, Comitê de Auditoria e Conselho Fiscal das empresas listadas na B3. A coleta dos dados ocorreu por meio de dados disponibilizados no website da B3, no formulário de referência e demonstrações financeiras, nos meses de fevereiro e março de 2018. Consequentemente, os dados relacionados ao ano de 2017 ainda não haviam sido divulgados pelas empresas, sendo analisado o triênio anterior.

A população da pesquisa representa as empresas listadas na B3, integrantes dos três níveis de governança corporativa: NM, N2 e N1. Compreendendo 152 empresas listadas nos anos 2014, 2015 e 2016, sendo 117 empresas do NM, 14 empresas do N2 e 21 empresas do $\mathrm{N} 1$, em que as empresas que não possuíam os dados necessários foram excluídas da amostra. A amostra é composta por empresas listadas nos três anos analisados e que possuem Comitê de Auditoria. Foram excluídas as empresas financeiras, por atenderem legislações específicas. Após os ajustes e exclusões, a amostra ficou composta por 62 empresas, sendo 49 do NM, 8 do N2 e 5 do N1.

O audit delay foi definido como a variável dependente do modelo, que corresponde ao número de dias compreendido entre o último dia do exercício social até a data de publicação das demonstrações financeiras. A pesquisa foi baseada nos resultados de pesquisas anteriores sobre o audit delay como: Afify (2009), Al-Ajmi (2008), Ashton, Graul e Newton (1989), Carslaw e Kaplan (1991), Cunha et al., (2015), Habib e Bhuiyan (2011), Ika e Ghazali (2012), Mande e Son (2011), Oussii e Taktak (2018), Pereira (2011), Cunha, Pletsch e Silva (2015).

Tendo como variáveis independentes as características do Conselho de Administração, definida pela proxies número de membros do Conselho, quantidade de membros independentes e dualidade; as características do Comitê de Auditoria têm como proxies: a 
expertise, número de membros independentes e número total de membros; para o Conselho Fiscal, utilizou-se como proxy, o número de membros e se existe Conselho Fiscal.

As variáveis de controle que compõem o modelo de regressão são: Índices Econômicos Financeiros, sendo o Retorno sobre o Ativo (ROA) e a liquidez corrente; Características da Empresa Auditada, como o porte e a divulgação de prejuízos; Características de Auditoria Independente, sendo Big Four e honorários de não auditoria. Os componentes do constructo são descritos no Quadro 1, em que é demonstrada a operacionalização das variáveis envolvidas na pesquisa.

Quadro 1 - Descrição das variáveis do modelo

\begin{tabular}{|l|l|}
\hline Audit_Delay & $\begin{array}{l}\text { Número de dias entre o encerramento do exercício social anterior e a emissão do } \\
\text { relatório de auditoria independente }\end{array}$ \\
\hline CA_IND & Número de membros do Conselho de Administração \\
\hline CA_NMEM & Número de membros independentes que fazem parte do Conselho de Administração \\
\hline CA_DUAL & $\begin{array}{l}\text { Variável Dummy: o Presidente do Conselho de Administração não é o Presidente da } \\
\text { Empresa 1, se não 0. }\end{array}$ \\
\hline CAUD_EXP & $\begin{array}{l}\text { Número de membros que fazem parte do Comitê de Auditoria com conhecimento em } \\
\text { contabilidade e finanças/auditoria }\end{array}$ \\
\hline CAUD_IND & Número de membros independentes que fazem parte do Comitê de Auditoria \\
\hline CAUD_NMEM & Número de membros do Comitê de Auditoria \\
\hline CF_NMEM & Número de membros do Conselho Fiscal \\
\hline CF_S_N & Variável Dummy: Conselho Fiscal, se possui assume 1, se não possui assume 0. \\
\hline ROA & Retorno sobre o Ativo \\
\hline LC & Liquidez corrente \\
\hline PORTE & Logaritmo natural dos ativos totais da empresa auditada \\
\hline DIV_PREJ & Variável Dummy: divulgação do Prejuízo, se sim assume 1, se não assume 0. \\
\hline TAM_FIRM_AUD & Variável Dummy: se Big Four assume 1, se não é Big Four 0. \\
\hline HON_N_AUD & Honorários de não Auditoria \\
\hline
\end{tabular}

Fonte: Dados da pesquisa.

Foram propostas variáveis para cada hipótese que compõem o modelo de dados em painel, para isso foi necessário estabelecer a variável dependente, que nesse caso, é o audit delay. Com isso, o modelo utilizado para análise é apresentado na equação 1 :

$$
A U D I T \_D E L A Y=\beta_{0}+\beta_{1}+\varepsilon
$$

Para tal, como procedimentos estatísticos, utilizou-se regressão de dados em painel com efeitos aleatórios, com uso do Software Gretl 2018 b-git. Desta forma, para a análise e interpretação dos dados são utilizados métodos estatísticos, sendo utilizada então a técnica de dados em painel, que segundo Zago e Mello (2016, p.440), "consiste em unidade de corte transversal acompanhada de um extenso tempo. Dessa forma os dados em painel se utilizam de uma dimensão espacial e outra temporal".

Conforme Gujarati (2006), existe uma maior variabilidade e menor colinearidade entre as variáveis nos dados em painel, uma vez que estes proporcionam maiores subsídios informativos. Além disso, esse método estatístico facilita a análise de séries temporais periódicas. Além de que, a regressão de dados em painel se torna relevante nessa pesquisa, visto que, por meio dela é possível realizar a análise tanto pela dimensão de cross-section (empresas), quanto pela dimensão temporal (períodos) (ZAGO, MELLO, 2016). 


\section{ANÁLISE E DISCUSSÃO DOS RESULTADOS}

A análise dos dados compreende os resultados com base na regressão de dados em painel, que foi utilizada para verificar a relação entre audit delay e as características do Conselho de Administração, Comitê de Auditoria e Conselho Fiscal das empresas listadas na B3. Inicialmente, aplicou-se o teste de Hausman para a definição do modelo de regressão a ser utilizado, com efeitos fixos ou efeitos aleatórios. De acordo com Andrade e Galina (2013, p. 249), "o teste de Hausman verifica a hipótese nula em que os coeficientes esperados pelo estimador dos efeitos aleatórios eficientes são os mesmos que o esperado pelo estimador dos efeitos fixos consistentes". O teste realizado apresentou p-value de 0.77685 , demonstrando que os efeitos aleatórios apresentaram estimativas mais consistentes, com isso, tornam-se mais eficientes os resultados, definindo assim, a utilização do modelo de regressão com efeitos aleatórios. Na Tabela 1 estão apresentados os resultados incluindo todas as variáveis do modelo, destacando as que registraram significância de até $10 \%$.

Tabela 1 - Modelo de Efeitos Aleatórios com todas as variáveis

\begin{tabular}{|c|c|c|c|c|c|}
\hline & Coeficiente & Erro Padrão & $\mathbf{z}$ & p-valor & \\
\hline Constante & 148,703 & 27,941 & 5,3220 & $<0,0001$ & $* * *$ \\
\hline CAUD_EXP & 0,8898 & 1,2619 & 0,7052 & 0,4807 & \\
\hline CAUD_IND & 1,5010 & 1,3392 & 1,1208 & 0,2624 & \\
\hline CAUD_NMEM & $-1,7426$ & 1,0357 & $-1,6825$ & 0,0925 & $*$ \\
\hline CA_IND & $-0,2389$ & 0,7150 & $-0,3342$ & 0,7382 & \\
\hline CA_NMEM & 0,3404 & 0,2968 & 1,1466 & 0,2515 & \\
\hline CF_NMEM & 2,6232 & 0,9128 & 2,8737 & 0,0041 & $* * *$ \\
\hline CF_S_N & $-14,2090$ & 6,8082 & $-2,0870$ & 0,0369 & $* *$ \\
\hline ROA & $-23,0336$ & 11,0582 & $-2,0830$ & 0,0373 & $* *$ \\
\hline LC & $-0,5224$ & 1,0483 & $-0,4983$ & 0,6183 & \\
\hline PORTE & $-5,8880$ & 1,7995 & $-3,2721$ & 0,0011 & $* * *$ \\
\hline TAM_FIRM_AUD & 4,6222 & 4,9405 & 0,9356 & 0,3495 & \\
\hline HON_N_AUD & $-0,0000$ & 0,0000 & $-0,9642$ & 0,3350 & \\
\hline DIV_PREJ & 4,7421 & 3,0939 & 1,5327 & 0,1253 & \\
\hline
\end{tabular}

Fonte: Dados da pesquisa.

Os resultados apresentados na Tabela 1 mostram, portanto, que as variáveis que apresentaram significância no modelo foram: CAUD_NMEM (número de membros do Comitê de Auditoria) com p-valor de 0,0925, o CF_NMEM (número de membros do Conselho Fiscal) com p-valor de 0,0041, o CF_S_N (existência de Conselho Fiscal) com p-valor de 0,0369, o ROA (Rentabilidade) com $p$-valor de 0,0373 e o PORTE com $p$-valor de 0,0011 . O relacionamento das variáveis com o audit delay está apresentando na sequência do estudo.

\subsection{ANÁLISE DAS VARIÁVEIS RELACIONADAS AO CONSELHO DE ADMINISTRAÇÃO}

As variáveis relacionadas ao Conselho de Administração foram: a independência, o número de membros e a dualidade. Quanto a dualidade, nenhuma das empresas na amostra apresentou essa característica. Desta forma, o presidente da empresa não ocupava o cargo de presidente do Conselho de Administração concomitantemente, desse modo, essa variável não foi incluída no modelo de regressão. A Tabela 2 demonstra o comportamento das variáveis do Conselho de Administração em relação ao audit delay, destaca-se, porém, que não houve significância estatística nessa relação. 
EDIÇÃO ESPECIAL: COMEMORATIVA AOS 45 ANOS DOS CURSOS DE GRADUAÇÃO EM CIÊNCIAS CONTÁBEIS E ADMINISTRAÇÃO DA UNOCHAPECÓ

Tabela 2 - Variáveis relacionadas ao Conselho de Administração

\begin{tabular}{lllll}
\hline & Coeficiente & Erro Padrão & z & p-valor \\
\hline Constante & 148,703 & 27,941 & 5,3220 & $<0,0001$ \\
Independência do CA & $-0,2389$ & 0,7150 & $-0,3342$ & 0,7382 \\
№ de membros do CA & 0,3404 & 0,2968 & 1,1466 & 0,2515 \\
\hline
\end{tabular}

Fonte: Dados da pesquisa.

Com isso, nota-se que o atraso na entrega do relatório de auditoria independente não apresenta relação com a quantidade de membros que compõe o Conselho de Administração, e não se relaciona com a independência desses membros. Sendo assim, rejeita-se a hipótese $\mathrm{H}_{1}$, a qual avalia se as características do Conselho de Administração influenciam no atraso de emissão de relatório de auditoria independente das empresas auditadas.

O resultado diverge do resultado encontrado por Afify (2009), em que essas mesmas variáveis impactaram significativamente no audit delay. A pesquisa foi realizada em mercados de capitais emergentes como o Cairo e Alexandria Stock Exchange (CASE) e, de acordo com Afify (2009), a associação negativa entre a independência do conselho de Administração e o audit delay pode impactar positivamente na qualidade divulgação financeira, e com isso, reduzir o atraso do relatório de auditoria independente.

\subsection{ANÁLISE DAS VARIÁVEIS RELACIONADAS AO COMITÊ DE AUDITORIA}

O Comitê de Auditoria é um mecanismo de governança corporativa que tem por função principal dar suporte ao Conselho de Administração, além de auxiliar na gestão das organizações quanto a restrição de conflitos de agência. No entanto, para que esse órgão desempenhe suas funções de forma mais independente e para que também possa repassar maior transparência e fidedignidade de suas informações aos interessados, deve possuir algumas características elencadas pelos órgãos de fiscalização tais como: tamanho, expertise e independência (BAIOCO, 2015; DE LUCA et al., 2010).

Pereira (2011) aponta que o prazo de entrega do relatório de auditoria está ligado a qualidade da informação, dessa forma, pressupõe-se que a qualidade das características do Comitê de Auditoria influencia na diminuição do prazo de entrega do parecer de auditoria. Ika e Ghazali (2012) garantem que a relação significativa entre as características do Comitê de Auditoria e o audit delay demonstram que há uma maior eficácia na qualidade dos relatórios financeiros. Os resultados encontrados na relação das variáveis de comitê de auditoria e audit delay são demonstrados na Tabela 3.

Tabela 3 - Variáveis relacionadas ao Comitê de Auditoria

\begin{tabular}{llllll}
\hline & Coeficiente & Erro Padrão & z & p-valor \\
\hline Constante & 148,703 & 27,941 & 5,3220 & $<0,0001$ & $* * *$ \\
Expertise do Comitê & 0,8898 & 1,2619 & 0,7052 & 0,4807 & 0,2624 \\
Independência do Comitê & 1,5010 & 1,3392 & 1,1208 & 0,0925 & $*$ \\
№ de membros do Comitê & $-1,7426$ & 1,0357 & $-1,6825$ & $*$
\end{tabular}

Fonte: Dados da pesquisa.

Dentre as variáveis analisadas, somente o número de membros demonstrou significância nos dados. De acordo com a CVM (2011), a quantidade ideal de membros é de no mínimo três e no máximo cinco, sendo preferencialmente que a maioria seja independente. $O$ resultado possui relacionamento negativo com coeficiente de $-1,74266$ e $p$ valor de 0,0925 , relevante, portanto, ao nível de significância de $90 \%$, ou seja, o número de 
membros do Comitê de Auditoria impacta negativamente no audit delay. Com isso, tem-se que, quanto maior for o número de membros do Comitê de Auditoria, menor tende a serem os dias de atraso para publicação do relatório de auditoria independente.

É plausível apontar que, com um maior número de membros no comitê, a gestão da empresa tende a ser mais receptiva em relação a aceitação dos relatórios e ajustes demandados pela auditoria externa. Corrobora com esse resultado o estudo de Cunha, Pletsch e Silva (2015) que confirmam em seus achados que a quantidade de membros que compõem o Comitê de Auditoria possui relação com o audit delay, concluindo que este é menor quando a quantidade dos membros é maior, havendo assim relação negativa entre o número de membros do Comitê de Auditoria e o audit delay.

A independência dos membros apresentou relacionamento positivo, porém sem significância estatística, portanto, a independência dos membros não exerce influência no audit delay das empresas da amostra. Oussii e Taktak (2018) corroboram esse resultado, expondo que a independência não está significativamente associada ao audit delay. Por outro lado, Cunha et al., (2015), encontraram resultado significativo nessa relação, indicando que o Comitê de Auditoria que possui mais membros independentes apresenta um menor prazo no audit delay. Depreende-se, portanto, que a relação entre essas duas variáveis não encontra consenso na literatura.

Em relação ao conhecimento dos membros nas áreas de contabilidade, auditoria ou finanças, denominada expertise, registrou relacionamento positivo, porém sem significância estatística. Depreende-se com isso, que a expertise dos membros do Comitê de Auditoria não tem influência sobre o audit delay. De acordo com os resultados, a hipótese $\mathrm{H}_{2}$, que relaciona se as características do Comitê de Auditoria influenciam no atraso de emissão de relatório de auditoria independente das empresas auditadas, foi aceita de forma parcial, visto que apenas o número de membros do Comitê de Auditoria foi significante, em linha com os resultados de Cunha, Pletsch e Silva (2015).

\subsection{ANÁLISE DAS VARIÁVEIS RELACIONADAS AO CONSELHO FISCAL}

O Conselho Fiscal é um órgão independente à administração da empresa e seu único objetivo é atender aos acionistas, ele não se reporta a nenhum outro órgão dentro da organização (IBGC, 2007; FURUTA, 2010). O Conselho Fiscal não se trata de um mecanismo obrigatório, sua deliberação tem caráter não permanente e é definido em assembleia (FURUTA 2010). O objetivo de elencar as empresas que possuem ou não Conselho Fiscal instalado consiste em verificar se a existência desse conselho exerce alguma influência no audit delay. Das 62 empresas da amostra, 38 possuem o Conselho Fiscal instalado, representando $61 \%$ das empresas analisadas.

Para averiguar tal suposição, foram selecionadas duas variáveis a serem analisadas. A primeira é se a empresa possuía ou não Conselho Fiscal instalado, a segunda variável foi à quantidade de membros existentes no Conselho Fiscal. A Tabela 4 demonstra os resultados encontrados na relação entre essas variáveis e o audit delay.

Tabela 4 - Variáveis relacionadas ao Conselho Fiscal

\begin{tabular}{llllll}
\hline & Coeficiente & Erro Padrão & Z & p-valor \\
\hline Constante & 148,703 & 27,941 & 5,3220 & $<0,0001$ & $* * *$ \\
№ de membros do CF & 2,6232 & 0,9128 & 2,8737 & 0,0041 & $* * *$ \\
Existência do CF & $-14,209$ & 6,8082 & $-2,0870$ & 0,0369 & $* *$ \\
\hline
\end{tabular}

Fonte: Dados da pesquisa. 
Os dados apresentados na Tabela 4 denotam que as variáveis relacionadas ao Conselho Fiscal são relevantes e significantes quanto ao audit delay. A existência do Conselho Fiscal instalado na empresa influencia negativamente o audit delay, com coeficiente de -14,209 e com significância ao nível de 95\%, com p-valor de 0,0369. Essa relação indica que a existência do Conselho Fiscal faz com que diminua os dias de atraso na publicação do relatório.

Por outro lado, o número de membros do Conselho Fiscal mostrou-se significante ao nível de 99\%, p-valor de 0,0041, e relacionamento positivo com coeficiente de 2,62321, ou seja, o número de membros influencia positivamente no atraso na entrega do relatório do auditor independente. Com base neste resultado é possível afirmar que quanto maior for à quantidade de membros que compõem o Conselho Fiscal, maior tenderá a ser o audit delay.

Com base nos resultados a hipótese $\mathrm{H}_{3}$, que aborda a influência do Conselho Fiscal no atraso de emissão de relatório de auditoria independente das empresas auditadas foi integralmente aceita, pois as variáveis evidenciaram significância.

$O$ intuito de verificar a influência do Conselho Fiscal com o audit delay está relacionado à escassez de pesquisas abordando essas duas variáveis. Cabe ressaltar que, não há estudos que utilizam essas duas variáveis em conjunto, um dos fatores que podem ser influenciadores de tal carência, pode estar relacionado com o fato de o Conselho Fiscal não ser um mecanismo obrigatório (FURUTA, 2010).

\subsection{ANÁLISE DAS VARIÁVEIS DE CONTROLE}

As variáveis de controle selecionadas para compor a análise foram: a rentabilidade do ativo, a liquidez corrente, o porte, auditoria por Big Four, os honorários de não auditoria e a divulgação do prejuízo, conforme mostra a Tabela 5.

Tabela 5 - Variáveis de Controle

\begin{tabular}{llllll}
\hline & Coeficiente & Erro Padrão & z & p-valor & $* * *$ \\
\hline Constante & 148,703 & 27,941 & 5,3220 & $<0,0001$ & $* *$ \\
ROA & $-23,0336$ & 11,0582 & $-2,0830$ & 0,0373 & $*$ * \\
LC & $-0,5224$ & 1,0483 & $-0,4983$ & 0,6183 & \\
Porte & $-5,8880$ & 1,7995 & $-3,2721$ & 0,0011 & 0,3495 \\
Auditada por Big Four & 4,6222 & 4,9405 & 0,9356 & 0,3350 & \\
Honorários de não auditoria & $-0,0000$ & 0,0000 & $-0,9642$ & 0,1253 \\
Divulgação do prejuízo & 4,7421 & 3,0939 & 1,5327 & &
\end{tabular}

Fonte: Dados da pesquisa.

$\mathrm{Na}$ Tabela 5, constata-se que apenas duas variáveis demonstraram significância estatística, a rentabilidade do ativo (ROA) foi significante ao nível de $95 \%$, com $p$-valor de 0,0373 e coeficiente negativo em -23,0336, isto é, à medida que a rentabilidade do ativo aumenta, o audit delay tende a diminuir. Da mesma forma, o relacionamento do porte da empresa foi negativo com o coeficiente de $-5,8880$ e significante ao nível de $99 \%$, com $p$-valor de 0,0011 , tal resultado indica que, com o aumento do porte da empresa, o número de dias do audit delay tende a diminuir.

Os resultados referentes às variáveis de rentabilidade do ativo e porte da empresa são semelhantes aos resultados encontrados por Al-Ajmi (2008), isso indica que grandes as empresas e as que possuem maior rentabilidade, provavelmente, passam pelo processo de auditoria mais cedo do que outras empresas. Conforme Oussii e Taktak (2018), as empresas que possuem maior rentabilidade podem requerer que o processo de auditoria em suas empresas seja concluído com maior rapidez, isso porque pretendem disponibilizar as demonstrações auditadas com maior agilidade ao público interessado. 
Oussii e Taktak (2018) corroboram com o resultado ao afirmar que o tamanho da empresa é significativo e influencia na pontualidade do relatório. Relatam que as empresas maiores são capazes de pressionar mais as firmas de auditoria e, além disso, por possuírem mais recursos, permitem a conclusão de uma auditoria mais rápida.

Segundo Pereira e Costa (2012), o auditor antecipa a emissão do relatório de auditoria quando seu cliente é maior, pois caso ocorra uma perda por parte desse cliente o impacto econômico será muito grande e poderá gerar altos custos para a firma. Al-Ajmi (2008) infere que quanto maior a empresa, mais ágil é a publicação de suas demonstrações.

$\mathrm{Na}$ variável divulgação do prejuízo, houve um relacionamento positivo, porém, insignificante ao audit delay. Pereira e Costa (2012) abordam que, quando há prejuízos o auditor tende a postergar a emissão do relatório gerando também uma maior quantidade de testes, resultado semelhante aos achados de Carslaw e Kaplan (1991).

A liquidez corrente possui um relacionamento negativo, ou seja, à medida que o índice aumenta o número de dias do audit delay tende a diminuir. Contudo, o resultado não teve significância e não representa impacto em relação ao prazo de divulgação. Com isto, essa variável não apresenta influência no prazo de entrega do relatório de auditoria. Em linha, Camargo e Flach (2016) relatam que, quando o índice de liquidez corrente é menor, os auditores podem demorar mais tempo para emitir o relatório. Com base nos resultados, as características da empresa auditada, porte e divulgação de prejuízo, os índices econômicos financeiros, rentabilidade dos ativos e liquidez corrente, influenciam no atraso de emissão de relatório de auditoria independente das empresas auditadas, foi aceita de forma parcial.

No que se refere às características da auditoria independente, em relação ao tamanho da firma de auditoria, o resultado encontrado não demonstra nenhuma relação significativa com o audit delay, o mesmo resultado foi encontrado por Pereira e Costa (2012). Por outro lado, os resultados divergem de Cunha et al., (2015), que encontraram que empresas auditadas por firmas de auditoria Big Four divulgam suas demonstrações financeiras em um prazo menor. Outra característica analisada da auditoria independente foram os honorários de não auditoria, que com base no resultado foi possível confirmar que não possuem relação significante com o audit delay. Este resultado diverge do resultado encontrado por Cunha et al. (2015), o qual demonstra que as empresas que mais utilizam serviços de não auditoria são as que mais atrasam o prazo de publicação do parecer.

Sendo assim, este estudo registra que o audit delay pode ser estimado com base em características do Comitê de Auditoria e Conselho Fiscal e pelo indicador de rentabilidade e do porte das empresas listadas na B3.

\section{CONSIDERAÇÕES FINAIS}

O atraso na publicação do relatório de auditoria, audit delay, é uma variável de mercado que pode prejudicar a imagem da empresa frente a seus stakeholders, visto que, o atraso pode ser sinal de problemas de gestão ou de resultados insatisfatórios na companhia. Nesse contexto, esse estudo analisou se a estrutura de governança de companhias de capital aberto, listadas na B3, apresenta algum relacionamento com o audit delay. Utilizou-se como variáveis de análise as características do Conselho de Administração, do Comitê de Auditoria e do Conselho Fiscal, e características econômicas relacionadas ao porte, rentabilidade, liquidez e divulgação de prejuízos da empresa.

Os resultados encontrados contribuem no sentido de que características do Comitê de Auditoria e do Conselho Fiscal influenciam no audit delay em empresas listadas, a partir da aplicação de regressão com dados em painel, apontaram que a estrutura do conselho de 
administração não exerce nenhuma influência no atraso da publicação do relatório de auditoria, assim como a liquidez e a divulgação de prejuízos.

Já as variáveis relacionadas ao conselho fiscal apresentaram resultados divergentes, o número de membros que forma o conselho fiscal mostrou relacionamento positivo com o audit delay, indicando que quanto maior for o conselho fiscal, maior é a tendência de que aumentem os dias de atraso na publicação do relatório de auditoria. Pode-se inferir que esse resultado esteja relacionado com o fato de que por serem mais membros no conselho, seja necessário mais tempo para que os conselheiros avaliem o relatório, ocasionando assim o atraso.

Por outro lado, o fato de existir conselho fiscal formalmente instalado na empresa, se mostrou negativamente relacionado com o audit delay, isso significa que se a empresa contar com o conselho fiscal em sua estrutura de governança, há a tendência de que o relatório de auditoria seja publicado com menos dias de atraso. Desse modo, conclui-se que a existência do conselho fiscal pode ser considerada benéfica para a empresa ao diminuir o atraso no audit delay, no entanto, a eficiência do conselho fiscal pode ser prejudicada pelo número de conselheiros que o compõe. Esse resultado não encontra precedentes em estudos anteriores, possivelmente porque o conselho fiscal não é um órgão obrigatório na estrutura de governança das companhias.

O comitê de auditoria, com a função de um órgão de fiscalização e controle na estrutura de governança, apresentou relacionamento negativo com o audit delay no que se refere ao número de membros que compõem o comitê. Deste modo, conclui-se que um maior número de membros no comitê de auditoria pode agilizar os procedimentos para elaboração e aprovação do relatório para que esse seja divulgado aos stakeholders com menos dias de atraso.

Os indicadores econômicos relacionados a estrutura corporativa da empresa demonstraram-se, também, negativamente relacionados com o audit delay. Depreende-se, portanto, que a rentabilidade do ativo (ROA) e o porte da empresa indicam que a medida que essas variáveis aumentam, o audit delay tende a diminuir, ou seja, quanto maior for a Companhia e quanto maior for o retorno auferido pelo ativo da Companhia, menos dias de atraso tendem a ocorrer na publicação do relatório de auditoria.

Ressalta-se ainda, como principal contribuição dessa pesquisa, a avaliação da influência do conselho fiscal no contexto de divulgação de informações corporativas aos stakeholders das Companhias listadas na bolsa. Como futuras pesquisas sobre o tema, sugerese ampliar a amostra para empresas não constantes da lista de segmentos diferenciados de governança corporativa, bem como a verificação de outras variáveis econômicas e não econômicas que podem exercer influência no audit delay.

\section{REFERÊNCIAS}

AFIFY, H.A.E. Determinants of audit report lag does implementing corporate governance have any impact? Empirical evidence from Egypt. Journal of Applied Accounting Research, v. 10, n. 1, p. 56-86, dez 2009.

AL-AJMI, J. Audit and reporting delays: Evidence from an emerging market. Advances in Accounting, v. 24, n. 2, p. 217-226, 2008. DOI: https://doi.org/10.1016/j.adiac.2008.08.002. 
ANDRADE, A. M. F.; GALINA, S. V. R. Efeitos da internacionalização sobre o desempenho de multinacionais e economias em desenvolvimento. Revista de Administração

Contemporânea (RAC), Rio de Janeiro, v. 17, n. 2, p. 239-262, mar./abr. 2013.

ASHTON, R. H.; WILLINGHAM, J. J.; ELLIOTT, R. K. An empirical analysis of audit delay. Journal of Accounting Research. Autumn, v. 25, n. 2, p. 275-292, 1987.

BAIOCO, V. G.; ALMEIDA, J. E. F. Efeitos Do Comitê de Auditoria E Do Conselho Fiscal Na Qualidade Da Informação Contábil No Brasil. Revista Contabilidade \& Finanças, São Paulo, v. 28 , n. 74, p. 229-248, ago. 2017. DOI: 10.1590/1808-

057x201703250https://www.jstor.org/stable/2491018?seq=1.

BAIOCO, V. G. Efeitos do Comitê de Auditoria e do Conselho Fiscal na qualidade da informação contábil no Brasil. 2015. Dissertação (Mestrado em Ciências Contábeis). Universidade Federal do Espírito Santo, Vitória, 2015.

BOWRIN, A. R. Review and syntesis of audit structure literature. Journal of Accounting Literature, v. 17, p. 40-71, 1998.

B3 - BRASIL, BOLSA, BALCÃO. Regimento Interno do Conselho de Administração da B3. 2016. Disponível em: < http://ri.bmfbovespa.com.br/fck_temp/26_2//Regimento_Interno_CA.pdf >. Acesso em 07 nov. 2017.

BRASIL. Lei 6.404, de 15 de dezembro de 1976. Dispõe Sobre As Sociedades Por Ações. Disponível em: <http://www.planalto.gov.br/ccivil_03/Leis/L6404consol.htm>. Acesso em 11 set. 2017.

CAMARGO, R. C. P. C.; FLACH, L. Audit report lag e expertise da firma de auditoria: uma análise com empresas listadas na BM\&FBovespa. Advances in Scientific and Applied Accounting, São Paulo, v. 9, n. 2, p. 181-201, mai./ago. 2016. DOI: 10.14392/ASAA.2016090204.

CARSLAW, C. A. P. N.; KAPLAN, S. An examination of audit delay: further evidence from New Zealand. Accounting and Business Research, v. 22, n. 85, p. 21-32, 1991. DOI: https://doi.org/10.1080/00014788.1991.9729414.

CUNHA, P. R. Proposta sistematizada de características e ações dos agentes internos da governança corporativa que possa contribuir à qualidade das demonstrações contábeis. 2011. 243 f. Tese (Doutorado em Ciências Contábeis e Administração) - Universidade Regional de Blumenau, Blumenau, 2011.

CUNHA, P. R.; PLETSCH, C. S.; SILVA, A. Relação entre as Características da Empresa, do Comitê de Auditoria e do Auditor Independente com o Prazo de Publicação das Demonstrações Financeiras. Revista de Educação e Pesquisa em Contabilidade, v. 9, n. 4, p. 415-429, out./dez. 2015. DOI: https://doi.org/10.17524/repec.v9i4.1232. 
CUNHA, P. R.; LUNELLI, L. O.; SANTOS, V. D.; FAVERI, D. B.; RODRIGUES JUNIOR, M. Relação entre as características do Comitê de Auditoria e o atraso da emissão do relatório de auditoria independente (Audit delay). Revista Contabilidade, Gestão e Governança, v. 18, n. 3, p. 47-65, set./dez. 2015.

DE LUCA, M. M. M.; MARTINS, L. C.; MAIA, A. B. G. R.; COELHO, A. C. D. Os mecanismos de Auditoria evidenciados pelas empresas listadas nos níveis diferenciados de governança corporativa e no novo mercado da BOVESPA. Revista Contabilidade Vista \& Revista, Belo Horizonte, v. 21, n. 1, p. 101-130, jan./mar. 2010.

FAMA, E. F.; JENSEN, M. C. Separation Of Ownership And Control. Journal of Political Economy, v. 26, n. 2, p. 288-307, jun, 1983. DOI: https://doi.org/10.1086/467037.

FONTES FILHO, J. R. Como andam as práticas de gestão e governança dos fundos de pensão no Brasil. IN: 25ㅇ Congresso da ABRAPP, outubro, Fortaleza. 2004.

FURUTA, F. A Relação das características das empresas com a adoção do Comitê de Auditoria X Conselho Fiscal adaptado. 2010. 189 f. Tese (Doutorado em Controladoria e Contabilidade) - Universidade de São Paulo, São Paulo, 2010.

GOTAÇ, D. de F.; MONTEZANO, R. M. S.; LAMEIRA, V. J. Governança Corporativa e Custos de Agência nas Empresas com Influência Governamental. Revista Sistemas \& Gestão, Rio de Janeiro, v. 10, n. 3, p. 408-425. 2015. DOI: https://doi.org/10.7177/sg.2015.V10.N3.A6.

HABIB, A.; BHUIYAN, M. B.U. Audit firm industry specialization and the audit report lag. Journal of International Accounting Auditing and Taxation, v.20, n. 1, p. 32-44. 2011. DOI: https://doi.org/10.1016/j.intaccaudtax.2010.12.004.

IKA, S. R.; GHAZALI, N. A. M. Audit committee effectiveness and timeliness of reporting: Indonesian evidence. Managerial Auditing Journal, v. 27, n. 4, p. 403-424. 2012. DOI: https://doi.org/10.1108/02686901211217996.

GUJARATI, D. Econometria básica. Rio de Janeiro: Elsevier, 2006.

INSTITUTO BRASILEIRO DE GOVERNANÇA CORPORATIVA. Guia de Orientação para o Conselho Fiscal. 2. ed. São Paulo, SP: IBGC, 2007. Disponível em: <http://www.ibgc.org.br/userfiles/1.pdf >. Acesso em 07 nov. 2017.

INSTITUTO BRASILEIRO DE GOVERNANÇA CORPORATIVA. Modelo de Regimento Interno de Conselho de Administração. São Paulo, SP: IBGC, 2008. Disponível em: < http://www.ibgc.org.br/userfiles/files/Caderno\%205.pdf>. Acesso em 07 nov. 2017.

INSTITUTO BRASILEIRO DE GOVERNANÇA CORPORATIVA. Guia de Orientação para Melhores Práticas de Comitês de Auditoria. São Paulo, SP: IBGC, 2009. Disponível em: <http://www.ibgc.org.br/userfiles/files/Guia_7_.pdf>. Acesso em 07 nov. 2017. 
IYOHA, F. O. Company attributes and the timeliness of financial reporting in Nigeria. Business Intelligence Journal, v. 5, n. 1, p. 41-49. 2012.

JENSEN, M. C.; MECKLING, W. H. Theory of the Firm: managerial behavior, agency costs and ownership structure. Journal of Financial Economics, v. 3, n. 4, p. 305-360, out, 1976. DOI: https://doi.org/10.1016/0304-405X(76)90026-X.

KASHIO, G. M. O Conselho de Administração como mecanismo de governança corporativa. 2007. Dissertação (Mestrado em Direito Político e Econômico) - Universidade Presbiteriana Mackenzie, São Paulo, São Paulo, 2007.

KRISHNAN, J. Audit Committee quality and internal control: an empirical analysis. The Accounting Review. v.80(2), p. 649-675. 2005. DOI:

https://doi.org/10.2308/accr.2005.80.2.649.

$L A M B, R$. Modelagem para uma investigação da efetiva função do conselho fiscal nas sociedades por ações brasileiras - relatório de pesquisa. EA/UFRGS, Porto Alegre, 2002.

MANDE, V.; SON, M. Do Audit delays Affect Client Retention? Managerial Auditing Journal, v. 26, n. 1, p. 32-50. 2011. DOI: https://doi.org/10.1108/02686901111090826.

MARTINEZ, A. L. "Gerenciamento" dos resultados contábeis: estudo empírico das companhias abertas brasileiras. 2001. Tese (Doutorado em Controladoria e Contabilidade: Contabilidade) - Universidade de São Paulo, São Paulo, 2001.

MARTINS, G. A.; THEÓPHILO, C. R. Metodologia da investigação científica para ciências sociais aplicadas. 2. ed. São Paulo: Atlas, 2009.

NG, P. P. H.; TAY, B. Y. K. An empirical examination of the determinants of audit delay in Hong Kong. British Accounting Review, v. 26, p. 43-59. 1994. DOI:

https://doi.org/10.1006/bare.1994.1005.

OLADIPUPO, A. O. Impact of corporate international linkage on the incidence of audit delay in Nigeria. Jorind, International Standard Serial Number, p. 231-237, jun, 2011. Disponível em: https://www.ajol.info/index.php/jorind/article/view/92620. Acesso em 06 dez. 2019.

OLIVEIRA, K. P. S. Assimetria informacional, qualidade da informação contábil e governança corporativa: características institucionais e organizacionais no mercado de capitais brasileiro. 2013. Dissertação (Mestrado em Ciências Contábeis) - Universidade de Brasília/UFPB/UFRN, João Pessoa, 2013.

OUSSII, A. A.; TAKTAK, N. B. Audit committee effectiveness and financial reporting timeliness the case of Tunisian listed companies. African Journal of Economic and Management Studies, n. 1, v. 9, p. 34-55. 2018. DOI: https://doi.org/10.1108/AJEMS-11-2016-0163. 
PEREIRA, A. N. Determinantes do atraso em auditoria externa (audit delay) em companhias brasileiras. 2011. Dissertação (Mestrado) - Fundação Instituto Capixaba de Pesquisas em Contabilidade, Economia e Finanças - FUCAPE, Espírito Santo, Vitória, 2011.

PEREIRA, A. N.; COSTA, F. M. Determinantes do atraso de auditoria externa (Audit delay) em companhias brasileiras. In: Encontro EnANPAD, 36. Rio de Janeiro. Anais [...]. Rio de Janeiro: ANPAD, 2012. Disponível em:

http://www.fucape.br/_public/producao_cientifica/2/ANTONIO.pdf

SANTOS, A. G. Comitê de Auditoria: uma análise baseada na divulgação das informações de empresas brasileiras. 2009. Dissertação (Mestrado em Ciências Contábeis) - Universidade de São Paulo, São Paulo, 2009.

SILVEIRA, A. D. M. Governança corporativa e estrutura de propriedade: determinantes e relação com o desempenho das empresas no Brasil. 2004. Tese (Doutorado em Administração) - Universidade de São Paulo, São Paulo 2004.

SOLOMON, S.; RECKERS, P. M.J.; LOWE, D. J. The impact of management image and nonaudit service fees on investors' perceptions of earnings quality. Advances in Accounting, v. 21, p. 199-216. 2005. DOI: https://doi.org/10.1016/S0882-6110(05)21008-8.

SORRENTINO, M. S. A. S.; TEIXEIRA, B.; VICENTE, E. F. R. Comitê de Auditoria: adequação às regras da SOX, Bacen, Susep e IBGC. Revista de Educação e Pesquisa em Contabilidade, v. 10, n. 3, p. 241-257, jul./set. 2016. DOI: https://doi.org/10.17524/repec.v10i3.1337.

ZAGO, C.; MELLO, DE G.R. Governança corporativa eletrônica e desempenho econômico e financeiro das empresas listadas no índice Bovespa. Revista Organização em Contexto, São Bernardo do Campo, n. 23, v. 12, p. 419-453, jan-jun 2016. 